\title{
Analysis of Zakir Naik’s Persuasion Discourse
}

\author{
Fatiam Tamim Alkhodari, Hadina Habil
}

\begin{abstract}
The present article examines how Dr.Zakir Naik, the celebrated Islamic preacher, uses language to persuade the audience in his popular speeches. The paper tests the persuasive approaches proposed in Connor and Lauer's model by segmenting a representative sample of Dr. Zakir Naik's You Tube video scripts into discourse units based on the three fundamental resources of persuasive appeals: Rationality, Credibility, and Affection.For the implementation of appeals, the types of convincing approaches were identified and analysed. Using manual transcription and NVivo 12 for codification and analysis, the findings reveal that logical strategies have been used predominantly in Zakir Naik's speeches. Amongst the Rational appeals, using authoritative sources has been mostly utilized. The results highlight that varied persuasion tactics show their functions in constructing the convincing power of his arguments.
\end{abstract}

Keywords: Persuasion, discourse analysis, contextual conditions, Zakir Naik, Islamic discourse

\section{INTRODUCTION}

In the field of discourse and communication, persuasion has been an important theme of investigation. Through persuasive communication, attitudes are changed, goals are accomplished, and interactions are proceeded. Therefore, the more knowledge people acquire about persuasive language, the better decision making they can have about delivering or accepting the delivered message [1].

Due to negative media misrepresentation of Islam accompanied with the occurrence of some social and political events, Islam phobia has spread in some communities [2], [3]. As a result, anti-Islam misconceptions and negative accusations became prevalent and, consequently, need to be answered back using well-grounded knowledge in both comparative religions and communication skills. Accomplishing this mission, Dr. Zakir Naik tried for more than two decades to interpret the truth about Islam and to refute misconceptions and accusations. Such a role gained him worldwide audience as well as granted him different titles, prizes, and criticism. Accordingly, such widespread speeches are worth studying closely in order to uncover the linguistic tools that contributed to his influence on diverse types of people from various cultures and backgrounds.

Even though several studies have addressed persuasion across types of genre, register, and community of practices [4]- [7], this study is the first of its kind in that it aims at investigating persuasion in the Islamic interactive oral discourse. In addition, the study highlights the importance of

Revised Version Manuscript Received on April 19, 2019.

Fatiam Tamim Alkhodari, Language Academy, Universiti Teknologi Malaysia/ Faculty of Social Sciences and Humanities/81310 UTM, Johor

Hadina Habil, Language Academy, Universiti Teknologi Malaysia/ Faculty of Social Sciences and Humanities/ 81310 UTM, Johor Bahru, Johor. Bahru, Johor.

affection strategies in persuasion. The work of this article revolves around the famous three axis of persuasion that correspond to Aristotle's artistic proofs, as Burke [8] describes them, that they need skill and effort in order to be brought into being. However, non-artistic proofs are ready-made; yet, they simply need to be recognized, taken off the shelf, and employed. In Aristotle's rhetorical theory, the artistic proofs are ethos (ethical proof), pathos (emotional proof), and logos (logical proof). Almost the same way, the adopted persuasive model is based on three main persuasive appeals: Credible, Affection, and Rational. The rational or intellectual strategies were based on Perelman and Olbrechts-Tyteca's [9] work with informal reasoning. However, Credibility and Affective appeals have been inspired by Aristotle, communication theorists, and modern psychologists.

\section{MATERIALS AND METHOD}

This paper takes on a qualitative research design by using discourse analysis to analyze Zakir Naik's persuasive discourse. To achieve the above-mentioned objectives, the study mainly addresses three research questions: (a) To what extent is Zakir Naik's discourse rational? (b) To what extent is Zakir Naik's discourse affective? (c) To what extent is Zakir Naik's discourse credible? According to Al-Nasher [10] the growing body of literature recognizes two basic approaches to study persuasion; the first centers on the analysis of the design of the speaker's messages which analyzes message form and organization, whereas the second approach studies the socio-psychological changes occurring to the receiver's attitude and behavior. Hence, this paper adopts the message-oriented approach. Rogers [11] notes that the adequate approach for studying persuasion and the one that is often favored by humanists, is the message-oriented approach.

The data consist of a representative collection of Zakir Naik's speeches, which were downloaded from his original YouTube Silver awarded channel named Dr. Zakir Naik. The collection contains answers to different question types from both genders and different religious beliefs. Each assigned video should meet the following criteria: having one addressee only, being Live at the time of videotaping to make sure it was naturally occurred speech, being presented in a well- known official TV channel or show, and having more than 4000 views as it is the minimum for popular videos in the You Tube filter. The videos were manually transcribed and imported to NVivo 12 where the scripts were coded according 
to the three appeals employed while each script was classified according to the questioners' demographic measured attributes, which are the questioner's gender type, question type, and religious belief. The codes were analyzed, and compared using Microsoft Excel, and then, interpreted.

\section{THEORETICAL MODEL}

Among persuasion books, studies, and strategies [12] - [17] Aristotle's three main persuasion tools (i.e. logos, pathos, and ethos) were the first and most comprehensive strategies. Moreover, scholars continue manipulating them. Thus, this study will adapt the three strategies, logos, ethos and pathos with all their sub-strategies. Practically, Connor and Luaer's [18] model generates more details of the three strategies and subdivides them. Even though Connor and Lauer's model has been applied in analyzing written tests, they indicated that it can be comprehensive to the "analyses of well-formed texts by expert persuaders to obtain more instances of effective use of a variety of appeals". Therefore, this study tests the applicability of this model with its subdivisions in analyzing religious oral discourse. Another advantage of adapting Connor and Luaer's persuasion system is to gain a detailed understanding of the structure of Zakir Naik's messages, thus, uncover the linguistic strategies employed in his speeches, which may contribute to their popularity. The sub-appeals that come under Rationality are Narrative examples, Descriptive example, Classification, Comparison, Contrast, Degree, Authority, Cause and effect-consequences, Model, Stage process, Ideal or Principle, and Detailed Information. Credibility appeals consist of Personal experience, Showing the speaker's respect for audience's interests and point of view, and Showing the persuader's good character and judgment. Lastly, Affection appeals comprise appealing to the audience's views, colorful pictures, and charged language.

\section{RESULTS AND DISCUSSION}

\section{A. Connor and Lauer's Persuasive Appeals}

Sociologists ensure that a truly convincing discoure is best identified by tracking how the three main appeals are applied [19]. What stands out in Fig. 1 is that the majority of the employed persuasive appeals were Rational; nonetheless, there was no significance difference between the other two appeals Credibility rating (30\%) and Affection rating (27\%). This finding supports [10]'s claim that religious propositions need to be logically based since they contribute in religious conventions.

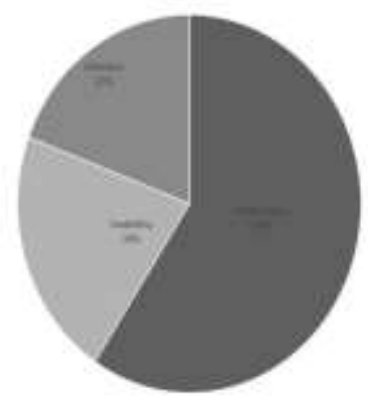

Figure 1 Connor and Lauer's System of persuasion in the Data

\section{A. Rationality Strategies}

Going into details, illustrated in Fig. 2, there is a remarkable result in the distribution of Rationality rating more than $(80 \%)$ of appeals in the data. However, among the rational approaches, using authoritative sources was mostly employed.

Authority-quoting approach uses either religious sources or a distinctive name that has a major effect on the audience. Thus, to rationalize his claims, Zakir Naik quotes from texts and sources that are "acceptable for the receivers" [20]. In order to support his statement, he chose to cite rather than paraphrase and this effectively gives the persuasive authority of his argument greater reliability. Thus, he cited verses from Yjurveda and Vedas (i.e. the ancient scriptures and texts for Hinduism) that "there is no image no photograph no painting no statue no idil" [21]. He also Quotes from Corinthians (i.e. a Christian scripture) to prove that women should cover their bodies. "Corinthians chapter number 11 verses 5 to 6 the woman that does not cover a head then she dishonored her head. A head should be shaved off' [22]. He also quotes Dr. Gracia, the chair of the evolutionary studies in Paris Rajan University in replying to Atheists regarding the theory of evolution [23].

The second and third mostly frequent of rational appeals were contrasting and comparing. Zakir Naik makes clear the similarities and differences between Islam and other religions to demonstrate his claim. For instance, he answers those who asked why we should follow Prophet Mohammed rather than the older Prophets; he said that as we always get the final edition of any book since it has the best updates, the same goes with the final prophet and the final Holly Book. Zakir Naik also compares "all the messages that came before were meant for a particular group of people, and the message was supposed to be followed for a particular time period. "Because Prophet Muhammad peace be upon him was the last and final messenger, he was not sent only for the Muslim of the Arabs, he was sent for all of humanity" [22]. Occasionally, Zakir Naik also compares between tangible examples that make the claims clearer for understanding. For instance, he answered those who asked about the prohibition of eating meat "if you analyze the teeth of the herbivorous animals, you find them flat teeth because they eat grass only, whereas carnivore animals have pointed teeth to facilitated eating flesh. However, the human teeth have both flat and pointed sets of teeth, which indicates that they are used for meat and vegetables" [24]. Then he quotes from Bhishma and Vedas to support his answers. In consequence, all the differences are further linked with several sacred religious verses in order to increase their authority.

Another significant appeal was using an ideal or principle. Such a strategy is built on the establishment of a universal assumption as Perlman [25] maintains that logic is what the recipient finds relevant for his thinking, since the concept of reality is linked with the universality of the assumption. Therefore, after the proposition has been accepted, the speaker calls for the common sense of the recipient. This is 
clear in one speech where Zakir Naik was answering a question that why does God punish people born in none Muslim families and did not know about Islam, Zakir Naik responded that only adults are punished as they are responsible to look for the truth especially in this open mediated world. He the ideal principle appeal that "if an adult tells the judge that I am robbing because my father taught me to rob, he will not be excused. Everyone is responsible for his or her own deed" [26].

Appeal to detailed information appeared in two respects: it either accompanies the authoritative source or is presented alone. An example for appeal to information alone "one more article came in 2005 in the same newspaper Sunday Times it said that $26 \%$ of the Britishers, they feel that wearing revealing clothes is partially or totally responsible for the rape. So, what I say that the more modest you are dressed up, you are respected more" [22]. Thus, adding information relevant to the claim maintains the legitimacy of the statements of the persuader.

Appeals to descriptive examples and narratives are utilized to show what is unsure and to give more information to clarify the proposal. For instance, to support the claim that the basic human instinct corresponds to Islam, Zakir Naik narrated the story of the two tribes who did not come in contact with modern civilization till as later in 1950; Aborigines and Kapowie; and researchers found that "Nevertheless, they did not call themselves Muslims. They believed in one God. They believed that God had got no images he had no idols" 26].

Concerning appeal to degree, it adds some clarification that two things are separated by a difference of degree rather than kind. This can be seen in his response: "whenever a non-Muslim accepts Islam the more appropriate word is 'revert' (raised tone of voice for emphasis) it's not converts. Convert means going from one faith to another faith. 'revert' means a person was on the right Faith, went to a wrong faith, and came back to the right faith" [26].

Appeal to cause and effect has been manipulated in Zakir Naik's speeches as it shows that the legitimacy of an idea can really be evaluated by its impact [25]. For instance, "if a child is born and non-Muslim family, before he gains maturity, if he dies, he will go to Jannah inshallah, now once a person becomes the adult it is a duty of that adult to find the truth" [26]. Thus, being a child is the only cause for those who die as non-Muslims to go to paradise and survive from punishment. However, adulthood is a reason for being responsible.

The least Rationality strategies used were appealing to classification, model, narrative example, and stage in process. Regarding appeal to classification, [18] indicate that 'classification' can be done by going from general concepts to the more specific. To cite an instance in responding to a question the reason Almighty God does not force all humans to be Muslims, Zakir Naik answers: "Almighty God has created various creation, and all the other creation of God besides human beings and Jinn, if they are not free of well at all, they would have become angels who are noble by their own. Whatever God says they follow.... the human beings have the free will to obey or disobey God" [27]. Naik also supports that by authoritative appeal by citing a verse from the Holy Quran. The series of moving from generalization to

specification legitimize the validity of the initially articulated proposal.

During appeal to model, the persuader establishes a rule for discussing questions and deducing conclusions.This approach promotes rational speech because it provides a mutual foundation for both interlocutors to defend their opinions. An example is "I tell all these human beings at least believe that there is one scripture which is $100 \%$ the Word of God ... Let us not fight over the differences let us agree to follow orders government and at least we'll be sure that what is common in all the three scriptures, this at least minimum is $100 \%$ the Word of God. What is different maybe the word of what may not be the Word of God" [21].

Appeal to stage in process is used when there is a gap between the accepted reality and what the persuader proposes. This approach mediates a step bridging the discourse gap [19]. An illustration is answering a Hindu who believes in his religion and thinks that there is a truth in all other religions. Thus, Zakir Naik replies, "previously our Creator sent messages which were there, but not complete because human being could not understand, could not grasp, as the message changes, he sent a new message and a new messenger, all calling for one God but with different rules and worships. That's the reason all the messages that came before the Quran they were meant for a particular group of people and meant to be followed for a particular time period". [21].

Overall, the above strategies indicate that Zakir Naik establishes his persuasion premises on authoritative sources from which he makes comparisons and contrasts with other sources, and then supports his answers with the rest of appeals.

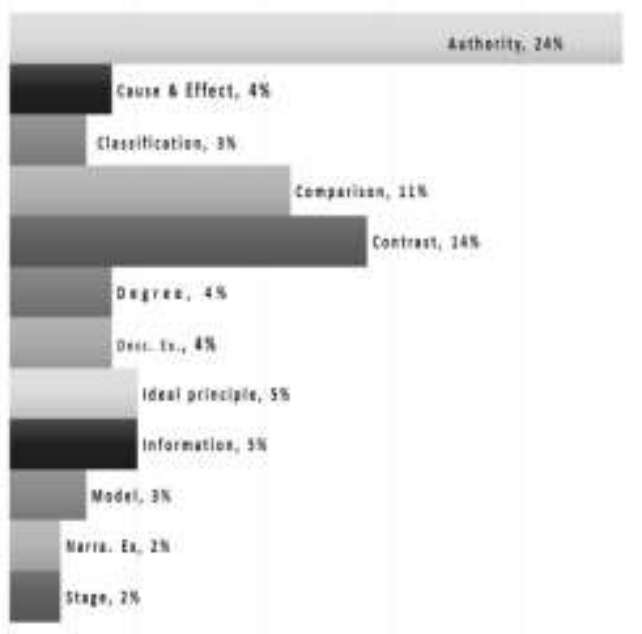

Figure 2 Rationality Strategies in the Data

\section{B. Credibility Strategies}

Even though credibility has substituted the concept of 'ethos', both mean the quality of being wise and moral, yet credibility includes more plausible scenarios [10]. Credibility appeals constitute more than $(30 \%)$ of the appeals. The results in Fig. 3 illustrate that the mostly used was appealing to respect through the use of terms like ' brother', 'sister', the addressee's proper name, and/or other gentle way of calling 
was the most dominant, thus, Zakir Naik showed respect and closeness.

Appeal to common interests was the second most dominant Credibility strategies. An illustration is when the persuader answers an interrogator, who is confused about the true religion, "all three sacred books say that you should not gamble all three say that it should not have pork, so let us agree to follow what is common, so you have to agree that there's one God" [24]. This approach helps create solidarity and decrease the gap between participants. It also demonstrates that the persuader recognizes other religion's features, thus building a positive attitude.

Appeal to personal experience was utilized through telling personal stories related to the claim such as when Zakir Naik told his dialogue: "one of the American told me your Eastern women they are not modest I had a shock, I said why? he told me your Eastern women you expose your belly so in American Western country, exposing belly is immodesty... there are different culture and there are different systems" [22]. Hence, visualizing the persuader in the story, therefore, makes the credibleness of the claim very important. [10].

The final Credibility strategy is showing good character and judgment. For example, "otherwise generally I per se if you analyze I have got no problem if the non-Muslims don't have nonveg brother if every non-Muslim in India starts having non-veg, then the price of mutton and will go high". This appeal emphasized the importance of being unbiased and objective in demonstrating judgment throughout persuasion. Using such Credibility appeals frequently could be explained that Zakir Naik considers himself as a representative of the religious beliefs and values he is arguing for; thus, he is trying to gain the audience in his side.

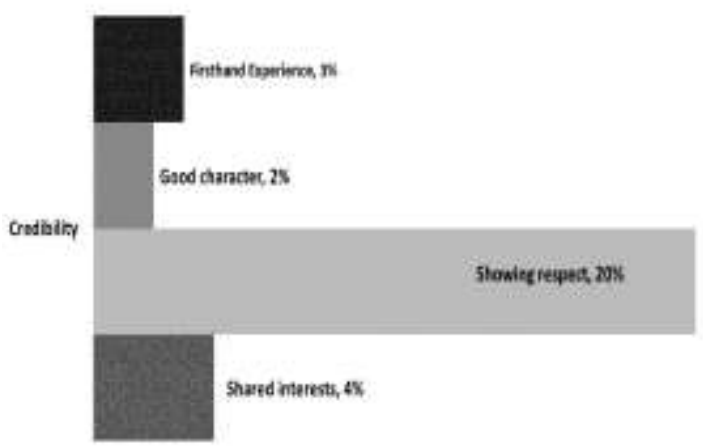

Figure 3 Credibility Strategies in the Data

\section{C.Affection Strategies}

Considering Affection appeal results, they help arouse the audience's emotion. Judgments are different while feeling pleased and friendly than being hurt and aggressive [10]. Affective appeals in the analysis made up to $(27 \%)$ of the appeals. The findings in Fig. 4 show that using charged language was employed consistently, while there was a slight difference between appeals to audience's views and values and the appeal to vivid pictures.

Examples of charged langue strategy can be found in "there is no book so far that I've read which talks about fact of evolution "and "no non-Muslim no human being even if he's put in hell will ever object to the justice of Allah". Such use of charged language reflects the persuader's high confidence and strong argument. The purpose of this appeal is to let the receiver experience feeling of "negative connotation" such as fear [19].

Appeal to the audience's view shows that the speaker accepts the audience's emotions and supports their statements. For instance, "if you are not a good Hindu if you are not a good Christian, you will never follow Prophet Mohammed salah Allahu Alyhi wasallam because Hindu scriptures say so" [21]. In the previous example, Zakir Naik legitimizes the audience's own view and just adds that it can lead them to his view.

Finally, appealing to vivid and colored pictures has been employed to link the audience imagery with the appeals. For instance, "Allah will directly put in the heart of every human being whether a Muslim or non-Muslim about the truth about one God" [26]. The recipient will, therefore, visualize the idea that the persuader conveys, thus stirring their emotions to accept the claim.

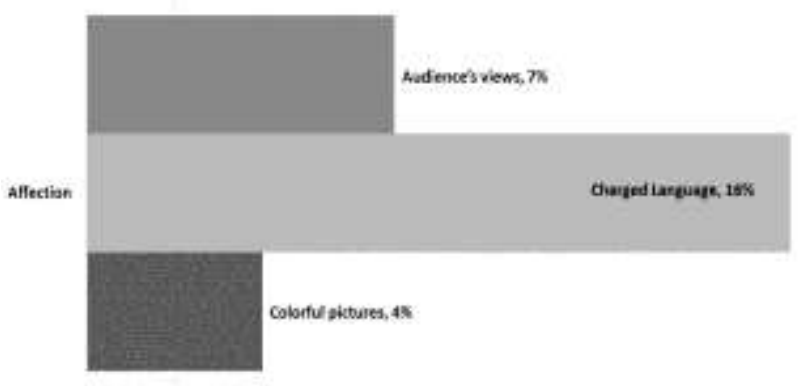

Figure 4 Affection Strategies in the Data

\section{V.CONCLUSION}

The purpose of the current article was to determine the persuasive strategies used by Dr. Zakir Naik through applying Connor and Lauer's [18] system of persuasion appeals in addressing different types of audiences. The study showed that Rationality appeals were more dominant than Credibility and Affective ones. Among Rationality appeals, however, the highest percentage was quoting authoritative sources. This implies Zakir Naik's high reliability on authentic religious sources throughout his replies. The results validate the importance of employing authority quotes appeal. The three appeals, however, were implemented for highlighting the authoritative approach, increasing the degree of certainty, maintaining the connection between the convincer and addressee, and promoting the understanding of the proposals discussed.

Moreover, the findings of the study will also help thinkers and educators to recognize the construction of the language and identity of Islamic preachers to be critical thinkers. Since 
the Zakir Naik's You Tube videos are studied scientifically, the findings will help in viewing the true strategies that Dr. Zakir Naik uses which contributed to the popularity of his speeches, thus helping anthropological students. In addition, the paper demonstrates that [18]'s model is applicable to analyze oral video recording discourse.

\section{ACKNOWLEDGMENT}

The success and outcome of this article required a lot of guidance and assistance from Dr. Hadina Habil, Dr. Muhammed Tamim, and Bashayer Baessa to whom is extreme privilege to have the completion of this article.

\section{REFERENCES}

1.J. Mulholland, A Handbook of practical strategies for improving communication. Routledge. 2005. [Online]. Available: https://b-ok.cc/book/915529/186df7

2.R. A. Bloul, (2003). "Islamophobia and anti-discrimination laws: ethnoreligion as a legal category in the UK and Australia". Presented at The Challenges of Immigration and Integration in the European Union and Australia, Sydney, 18-20 February 2003. University of Sydney. [Online]. Available: https://openresearch-repository.anu.edu.au/bitstream/1885/4109 6/3/bloul_paper.pdf

3. C. Allen, Islamophobia. 2016. Routledge.

4. P. Cotterell, and M. Turner. Linguistics and Biblical Interpretation. Downers Grove: InterVarsity Press. 1989

5. J. P. Dillard, and M. Pfau, The Persuasion Handbook: Developments in Theory and Practice. Thousand Oaks, CA: Sage Publications, 2002, [Online]. Available: https://bit.ly/2XtGsL3

6. T. Virtanen, and H. Halmari, "Persuasion across genres: Emerging perspectives", In: Persuasion across Genres. H. Halmari, and T. Virtanen, (eds) Amsterdam and Philadelphia: John Benjamins. 3-24. 2005. [Online]. Available: https://b-ok.cc/book/1084133/792801

7. M. Adam, (2019). "Persuasion in religious discourse: Enhancing credibility in sermon titles and openings". Discourse and Interaction, 10(2), pp5-25. [Online]. Available: https://www.ceeol.com/search/article-detail?id=762004

8. M. Burke, Stylistics: from Classical Rhetoric to Cognitive Neuroscience. The Routledge Handbook of Stylistics, Routledge. Abingdon, NY: 2014. pp1-9 [Online]. Available: https://b-ok.cc/book/2483840/7dff34

9. C. Perelman, and L. Olbrechts-Tyteca, The New Rhetoric (J. Wilkinson \& P. Weaver, Trans.) Notre Dame, IN: University of Notre Dame Press. (Original work published 1958), 1969. [Online]. Available: https://link.springer.com/chapter/10.1007/978-94-009-9482-9_ 1

10. A. Al-Nasher, Persuasion Strategies in Religious Discourse with Reference to Deedat's The Choice: Islam and Christianity. (PhD dissertation), Department of Foreign Languages KAU, Jed, KSA 2010. Accessed on Sep, 19th, 2018. [Online]. Available: https://bit.ly/2YDoUsv

11. W. Rogers, Persuasion: Messages, Receivers, and Contexts. Rowman \& Littlefield Pub Incorporated, 2007. [Online]. Available:

https://www.amazon.com/Persuasion-Messages-Receivers-Willi am-Rogers/dp/0742536742

12. H. Rank, "Teaching about public persuasion". In D. Dieterich (Ed.), Teaching and doublespeak. Urbana, IL: National Council of Teachers of English, 1976.

13. B. G. Rule, G. L. Bisanz, and M.Kohn, “Anatomy of a persuasion schema: Targets, goals, and strategies". Journal of Personality and Social Psychology, 48(5), pp. 1127-1140, 1985. Accessed on Sep, 22nd, 2018 [Online]. Available: http://dx.doi.org/10.1037/0022-3514.48.5.1127

14. J. Mulholland, A Handbook of Persuasive Tactics: A Practical Language Guide. Routledge, 2003. [Online]. Available: https://b-ok.cc/book/747380/80f345

15. C. Larson, Persuasion: Reception and Responsibility. Nelson Education, 2012. [Online]. Available: https://b-ok.cc/book/1222074/d2ad17
16. T. Manning,. The art of successful persuasion: seven skills you need to get your point across effectively. Industrial and Commercial Training, 44(3), 150-158, 2012. Accessed on Sep, 22nd, 2018. [Online]. Available: https://www.emerald.com/insight/content/doi/10.1108/0019785 1211216754/full/html

17. R. Jones, Communication in the Real World: An Introduction to Communication Studies. 2016. [Online]. Available: http://open.lib.umn.edu/communication/

18. U. Connor, and J. Lauer, (). "Understanding persuasive essay writing: Linguistic/rhetorical approach". Text-Interdisciplinary Journal for the Study of Discourse, 5(4), 309-326. 1985 Accessed on Sep. 16, 2018. [Online]. Available: https://www.degruyter.com/view/j/text.1.1985.5.issue4/text.1.19 85.5.4.309/text.1.1985.5.4.309.xml

19. D. Biber, U. Connor, and T. A. Upton, Discourse on the move: Using Corpus Analysis to Describe Discourse Structure (Vol 28). John Benjamins Publishing. 2007. [Online]. Available: https://bit.ly/2RY4R5w

20. M. Dainton, and E. D. Zelley, Applying Communication Theory for Professional Life: A Practical Introduction, 4th ed. Sage publications. $2018 . \quad$ [Online]. Available: https://b-ok.cc/book/5005113/62dd75

21. Dr Zakir Naik. If Everyone's God Is the Same, Then Why Many Religions? By Dr Zakir Naik. Oct. 28, 2014. Accessed on Dec 1st, 2018. [Video file]. Available: https://www.youtube.com/watch?v=6LClX8BR63A\&feature=y outu.be

22. You Knowy. اوك سد فورد بـ جامعة ذاي ك لـ ذاكر رائ عة اجاب ات. Jan. 6, 2016. Accessed on Dec, 3d, 2018. [Video file]. Available: https://www.youtube.com/watch?v=Tq4_zsaMGrc\&feature=you tu.be

23. Fairy Tale. Ex-Muslim Atheist Owns Stupid Zakir Naik on Evolution. Sep. 13, 2015. Accessed on Dec, 9th, 2018. [Video file]. Available: https://www.youtube.com/watch?v=sXa-UQjSNn0\&t=359s

24. Dr Zakir Naik. Killing an Ant or Any Living Creature is Wrong. Why Do Muslims then Have Non-Veg. Food? Sep. 27, 2014 Accessed on Dec 3rd, 2018 [Video file]. Available: https://www.youtube.com/watch?v=hnxmHXldXls\&feature=yo utu.be

25. C. Perelman, The Realm of Rhetoric, trans. W. Kluback, University of Notre Dame Press, Notre Dame. 198. [Online]. Available: https://b-ok.cc/book/2554058/d9e324

26. Ask4gain. Very Important Answer for All Non-Muslim - Dr.Zakir Naik. Dec. 16, 2017. Accessed on Dec, 6th, 2018. [Video file] Available: https://www.youtube.com/watch?v=Qk0-aXLk7_E

27. Islam The Light of The Heart. Critical Questions Asked by a Japanese Lady Dr Zakir Naik. Feb. 28, 2017. Accessed on Dec, 4th, 2018. [Video file]. Available: https://www.youtube.com/watch?v=V10QRa2vX9I\&t=42s

\section{AUTHORS PROFILE}

Fatima Alkhodari received her BA and MA from Taif university in 2011 and 2016 respectively with honor Degrees in both levels. Her research interests include Discourse analysis, Language and Communication, and Sociolinguistics. She is now working toward her PhD at UTM.

Hadina Habil ASSOC. PROF. in Language Academy UTM. She got her BA from USA in Business Management, her M. Sc in TESP in UK, Diploma in TESL from Selangor. And Ph.D. in Language and Communication from UPM. Her main areas of interests are Discourse Analysis, EFSP, and Language and Communication. 